\title{
Seroprevalence of Brucellosis in Large and Small Ruminants in Chhattisgarh state, India
}

\author{
Sanjay Shakya ${ }^{1 *}$, Anil Patyal ${ }^{1}$, Bhoomika ${ }^{1}$, Choodamani Chandrakar ${ }^{1}$, \\ Sandeep Indurkar ${ }^{1}$ and Dhirendra Bhonsle ${ }^{2}$ \\ ${ }^{1}$ Department of Veterinary Public Health and Epidemiology, College of Veterinary Science \\ and A.H., CGKV, Durg, Chhattisgarh-491001, India \\ ${ }^{2}$ Department of Livestock Production Management, College of Veterinary Science and \\ A.H., CGKV, Durg, Chhattisgarh-491001, India \\ *Corresponding author
}

\section{A B S T R A C T}

The present study was undertaken to determine the prevalence of brucellosis in small and large ruminants in state of Chhattisgarh, India. A

\section{Keywords}

Ruminants,

Brucellosis, I-

ELISA, Zoonoses,

Chhattisgarh

Article Info

Accepted:

26 May 2020

Available Online:

10 June 2020 total of 1050 sera samples from cattle $(n=750)$, buffaloes $(n=95)$, goats $(n=$ $170)$ and sheep $(n=35)$ were collected and tested for the presence of antibrucella antibodies by indirect enzyme-linked immunosorbent assay (IELISA) kits. The overall prevalence of brucellosis in cattle, buffaloes, goats and sheep was found $12.13 \%, 20 \%, 11.17 \%$ and $5.71 \%$, respectively. In case of large ruminants statistically significant difference $(\mathrm{P} \leq 0.05)$ in seroprevalence was observed for different district and, between cattle and buffaloes. However, in case of small ruminants statistically non-significant difference $(\mathrm{P} \geq 0.05)$ in seroprevalence was observed between districts, species and sex. The result of the study pointed out a major impact on health and productivity of animal population, and thus poses a greater risk for occupational transfer of zoonotic brucellosis to the human population.

\section{Introduction}

Brucellosis is a highly contagious and one of the most widespread zoonotic diseases in the world. It is reported to be endemic in many developing countries of Africa, Asia and Latin America. Nevertheless a high burden of brucellosis in many areas of the world, it is rarely emphasized by health systems and is still considered as neglected zoonoses by the World Health Organization (WHO) (Franc et al., 2018) and World Organization for Animal Health (OIE) (OIE, 2017). The disease is caused by different species of Brucella and most of the species of Brucella can infect multiple animals' species, including humans 
(Godfroid et al., 2010). In cattle, the infection is mostly caused by $B$. abortus, less frequently by $B$. melitensis and sometime by B. suis (OIE, 2016). In animals, brucellosis mainly causes chronic infection, with preferred localization in the reproductive system of the sexually mature female cattle, produces placentitis followed by abortion, leading to the huge production losses in terms of reduced milk production, abortion, weak off spring, weight loss, cull and condemnation of infected animals due to infertility, lameness and impediment for trade and export (UlIslam et al., 2013). Most of the infected animals abort only once in their lifetime, but they may remain infected for their entire life (Godfroid et al., 2010) and acts as reservoir of brucellosis for other animals and humans. In humans, the symptoms of disease include weakness, joint and muscle pain, headache, undulant fever, hepatomegaly, splenomegaly, drenching night sweats and chills, marked asthenia and anorexia (Hugh-Jones, 2000). Brucellosis causes persistent infection by its capacity to escape from innate and adaptive immunity and at present there is no vaccine available for prevention of brucellosis in humans (Shome et al., 2019). Hence, prevention of brucellosis in humans can be achieved by controlling the disease in animals.

Apart from the zoonotic potential, brucellosis is also poses a serious occupational health hazard for humans, and has been reported to be associated with farm workers, veterinarians, veterinary pharmacists, animal attendants, abattoir workers and laboratory attendants (Hull and Schumaker, 2018). Brucellosis is an increasingly significant veterinary and public health problem in India as the $80 \%$ of the population depends on livestock for their livelihood and for that they live in close contact with domestic animal population owing to their occupation. It is transmitted to humans through consumption of unpasteurized dairy products and uncooked meat or through direct contact with infected animals, placentas or aborted fetuses (Dean $e t$ $a l ., 2012)$. India with the world's largest dairy herd ranked first in terms of total milk production and contributing about $17 \%$ of the world's total milk production (FAOSTAT, 2015). Large vegetarian population of India relies on the milk and milk products for high quality proteins of animal origin, and around 70 million households engage in milk production (Douphrate et al., 2013). Brucellosis has become endemic throughout all Indian states in different species of livestock (Singh et al., 2015). It has been already reported from organized and unorganized dairy sector through national surveys (Shome et al., 2014; Chand and Chhabra, 2013; Jagapur et al., 2013). Recently, a large random sampling survey was undertaken in 15 states of India and reported the true prevalence of brucellosis in cattle and buffaloes (Shome et al., 2019).

The incidence of infection in animal reservoirs provides a key to its occurrence in humans also. Therefore, the correct and early diagnosis is of paramount importance in prevention and control of disease in animals. Further, data on status of prevalence of brucellosis in ruminants from state of Chhattisgarh is scanty. In view of the above facts, the present investigation was undertaken to assess the prevalence of brucellosis in various livestock species (cattle, buffaloes, goats, sheep) in Chhattisgarh.

\section{Materials and Methods}

The study was conducted in cattle, buffaloes, goats and sheep of Durg, Rajnandgaon, Korba, Raipur and Balod districts of Chhattisgarh, India. These districts come under plane agroclimatic zone of Chhattisgarh. The climatic condition of the state is tropical dry sub-humid type with 
average annual rainfall around $1400 \mathrm{~mm}$ and temperature varies between $5-25^{\circ} \mathrm{C}$ in winter and between $30-45^{\circ} \mathrm{C}$ in summer. Majority of livestock in the study area are non-descript and reared by small and marginal farmers under traditional system.

\section{Sample collection}

A total of 1050 sera samples from cattle $(n=750)$, buffaloes $(n=95)$, goats $(n=170)$ and sheep $(n=35)$ were collected randomly from the Durg, Rajnandgaon, Korba, Raipur and Balod districts of Chhattisgarh. After proper restraining the animal, approximately 5-7 ml of blood was collected from the jugular vein of each animal using vacutainers without EDTA. Samples were labelled using codes describing district names and species. The clotted blood in the tube was centrifuged at $1000 \mathrm{~g}$ for $10 \mathrm{~min}$ to obtain clear serum. All the sera samples were stored in $2 \mathrm{ml}$ vial at $20^{\circ} \mathrm{C}$ in laboratory till further analysis.

\section{Serodiagnosis of samples by Enzyme- linked Immunosorbent Assay (ELISA)}

For serodiagnosis of brucellosis Protein-G based indirect ELISA (i-ELISA) kit for bovine brucellosis and i-ELISA Kit for sheep and goat brucellosis were procured from National Institute of Veterinary Epidemiology and Disease Informatics (NIVEDI), Bengaluru. The procedure outlined in the instruction manual was followed for detection of antibodies in samples. The results were expressed as percent positivity (PP) values. The PP values used for the diagnostic interpretations were calculated using the following formula:

$\mathrm{PP}=$

Average OD value of test serum

Median OD of the strong positive control sera
Bovine sera sample that gave PP value 55\% to $65 \%$ is considered moderate positive and more than $65 \%$ as strong positive. Sample showed a PP value of below 55\% is taken as negative and sample with PP value of only $55 \%$ was re-tested. Goats and sheep sera sample with PP value of more than $54 \%$ was considered as positive, below 54\% was considered as negative and sample showed PP value $54 \%$ was re-tested.

\section{Statistical analysis}

Data obtained from serological test were analyzed by using SPSS version 20.0 for windows. Chi square test was used for analysis of risk factors like species and sex. The difference was considered statistically significant when the $\mathrm{p}$ value was found equal or less than 0.05 as per method described by Snedecor and Cochran (1994). Further, the odd ratio (OR) was calculated using a $2 \times 2$ contingency table.

\section{Results and Discussion}

\section{Seroprevalence of brucellosis in cattle and} buffaloes

Brucella infection in cattle and buffaloes was detected by i-ELISA kit. Out of 845 cattle and buffaloes sera samples tested, 110 were found positive for brucella antibodies (Table 1). The prevalence among districts ranges from $5.00 \%$ to $22.00 \%$. The prevalence of brucellosis was significantly $(\mathrm{P} \leq 0.05)$ higher in buffaloes $(20.00 \%)$ as compared to cattle $(12.13 \%) \quad(\mathrm{OR}=0.55 ; 95 \% \quad \mathrm{CI}=0.31-0.96$; $\mathrm{P}=0.005$ ). The $21.11 \%$ sera samples of female buffaloes and $12.17 \%$ sera samples of cows were found positive for brucella antibodies.

Seroprevalence of bovine brucellosis have been assessed during various periods from different regions of India (Patel et al., 2014; Chand and Chhabra, 2013; Kumar et al., 
2009). An overall $13.01 \%$ of seroprevalence of brucellosis was reported in various districts of Chhattisgarh. The $8.3 \%$ and $3.6 \%$ seroprevalence of brucellosis in 9236 cattle and 2818 buffaloes, respectively from 15 states of India was also reported (Shome et al., 2019). The highest prevalence of brucellosis $(22.00 \%)$ in present study was observed in Korba district (Table 1) which may be due to extensive movement of animals in the district. The correlation (0.27) between disease and higher animal population has been reported by different researchers (Jain $e t$ al., 2017; Dhand et al., 2005). The prevalence rates of $28.06 \%$ (Shakya et al., 1995), 31.2\% (Nitu et al., 2013) and $14.17 \%$ (Jain et al., 2017) were also reported in cattle in Chhattisgarh. The variation in prevalence rates may be attributed to sensitivity and specificity of different diagnostic techniques used in the studies.

The statistically significantly higher seroprevalence was found in buffaloes $(20.00 \%)$ than in cattle $(13.01 \%)$ in the present study, which corroborates the findings of Dhand et al., (2005). In contrast higher seroprevalence in cattle as compared to buffaloes was also reported (Saini et al., 1992). The various risk factors viz. herd size, gregarious nature, organized farms, source of animals etc are responsible for higher prevalence of brucellosis in cattle and buffaloes.

\section{Seroprevalence of brucellosis in sheep and goats}

Seroprevalence of brucellosis in sheep and goats was found to be $10.24 \%$, which ranges from 7.00-13.33\% (Table 2). Earlier, 6.02\% seropositivity in caprine by i-ELISA was also reported (Sadhu et al., 2015). The variation in prevalence rate might be due to sex, age, breed, environment, breeding system etc. The statistically non significant $(\mathrm{P} \geq 0.05)$ higher seroprevalence of $11.17 \%$ in goats in comparison to $5.71 \%$ in sheep were observed during the present study. Rahman et al., (2011) also reported higher prevalence of brucellosis in caprine than ovine.

Table.1 Seroprevalence of brucellosis in cattle and buffaloes by i-ELISA in different districts of Chhattisgarh

\begin{tabular}{|l|l|l|l|l|l|l|l|}
\hline \multirow{2}{*}{ District } & \multicolumn{5}{|c|}{ No. of samples positive / No. of samples tested (\%) } & \multirow{3}{*}{ Total } \\
\cline { 2 - 7 } & Male & Female & Total & Male & Female & Total & \\
\hline \multirow{2}{*}{ Durg } & $2 / 9$ & $20 / 209$ & $22 / 218$ & $0 / 2$ & $18 / 68$ & $18 / 70$ & $40 / 288$ \\
& $(22.22 \%)$ & $(9.56 \%)$ & $(10.09 \%)$ & $(0.00)$ & $(26.47 \%)$ & $(25.71 \%)$ & $(13.88 \%)$ \\
\hline Rajnandgaon & $1 / 16$ & $34 / 259$ & $35 / 275$ & $0 / 2$ & $0 / 9$ & $0 / 11$ & $35 / 286$ \\
& $(6.25 \%)$ & $(13.12 \%)$ & $(12.72 \%)$ & $(0.00 \%)$ & $(0.00 \%)$ & $(0.00 \%)$ & $(12.23 \%)$ \\
\hline Korba & 0.00 & $22 / 100$ & $22 / 100$ & 0.00 & 0.00 & 0.00 & $22 / 100$ \\
& $(0.00 \%)$ & $(22 \%)$ & $(22 \%)$ & $(0.00 \%)$ & $(0.00 \%)$ & $(0.00 \%)$ & $(22 \%)$ \\
\hline Raipur & $0 / 1$ & $7 / 56$ & $7 / 57$ & $0 / 1$ & $1 / 13$ & $1 / 14$ & $8 / 71$ \\
& $(0.00 \%)$ & $(12.50 \%)$ & $(12.28 \%)$ & $(0.00 \%)$ & $(7.69 \%)$ & $(7.14 \%)$ & $(11.26 \%)$ \\
\hline Balod & $0 / 1$ & $5 / 99$ & $5 / 100$ & 0.00 & 0.00 & 0.00 & $5 / 100$ \\
& $(0.00 \%)$ & $(5.05 \%)$ & $(5.00 \%)$ & $(0.00 \%)$ & $(0.00 \%)$ & $(0.00 \%)$ & $(5.00 \%)$ \\
\hline \multirow{2}{*}{ Total } & $3 / 27$ & $88 / 723$ & $91 / 750$ & $0 / 5$ & $19 / 90$ & $19 / 95$ & $110 / 845$ \\
& $(11.11 \%)$ & $(12.17 \%)$ & $(12.13 \%)$ & $(0.00 \%)$ & $(21.11 \%)$ & $(20.00 \%)$ & $(13.01 \%)$ \\
& & & & & & & \\
\hline
\end{tabular}


Table.2 Seroprevalence of brucellosis in goats and sheep by i-ELISA in different districts of Chhattisgarh

\begin{tabular}{|l|c|c|c|c|c|c|c|}
\hline \multirow{2}{*}{ District } & \multicolumn{7}{|c|}{ No. of samples positive / No. of samples tested (\%) } \\
\cline { 2 - 8 } & \multicolumn{7}{|c|}{ Total } \\
\cline { 2 - 8 } & Male & Female & Total & Male & Female & Total & \\
\hline \multirow{2}{*}{ Durg } & $0 / 17$ & $7 / 68$ & $7 / 85$ & $0 / 2$ & $0 / 13$ & $0 / 15$ & $7 / 100$ \\
& $(0.00 \%)$ & $(10.29 \%)$ & $(8.23 \%)$ & $(0.00 \%)$ & $(0.00 \%)$ & $(0.00 \%)$ & $(7.00 \%)$ \\
\hline \multirow{2}{*}{ Rajnandgaon } & $1 / 14$ & $11 / 71$ & $12 / 85$ & $0 / 2$ & $2 / 18$ & $2 / 20$ & $14 / 105$ \\
& $(7.14 \%)$ & $(15.49 \%)$ & $(14.11 \%)$ & $(0.00 \%)$ & $(11.11 \%)$ & $(10.00 \%)$ & $(13.33 \%)$ \\
\hline Total & $1 / 31$ & $18 / 139$ & $19 / 170$ & $0 / 4$ & $2 / 31$ & $2 / 35$ & $21 / 205$ \\
& $(3.22 \%)$ & $(12.94 \%)$ & $(11.17 \%)$ & $(0.00 \%)$ & $(6.45 \%)$ & $(5.71 \%)$ & $(10.24 \%)$ \\
\hline
\end{tabular}

The difference in seroprevalence among female and male animals was also statistically non significant. Similar rates of seroprevalence of $8.51 \%$ in goats and $6.66 \%$ in sheep were earlier recorded in Chhattisgarh (Sai et al., 2018). The higher prevalence of brucellosis in female as compared to male may be due to high concentration of erythritol in female reproductive organs, which is scarcely present in male animals (Colmenero et al., 2007).

Brucellosis is one of the challenging issues for human and animal health, it is the second most important zoonoses after rabies and prevalent in number of developing countries including India. Many factors such as absence of a country wide control policy, unawareness of farmers to vaccinate young female calves, non-implementation of test and slaughter policy and usual practice of selling positive reactor animals to other farmers are possible reasons for the spread of this disease among livestock in India. The statistically non significant seroprevalence of $13.01 \%$ and $10.00 \%$ was observed in large and small ruminants, respectively during the present study. This may be due to the predominant extensive animal husbandry practices of the state which provides a good opportunity for mixing of different animal's species at communal grazing areas and watering points. These conditions facilitate the transmission of disease among various animal species.
In conclusion, the study revealed seropositivity of $14.17 \%$ for large ruminants and $10.24 \%$ for small ruminants in Chhattisgarh, indicating alarming condition for the dairy sector in the state. The higher prevalence in animals poses potential risk of brucellosis transmission to farmers, livestock owners and dairy product consumers. Brucellosis in humans can be reduced by controlling this disease in animal population. Therefore to control this disease among humans, a joint venture among veterinary and public health professionals is very essential. Vaccination is the best way to control the spared of disease in heathy stock. The awareness campaign among high risk group viz. veterinarians and livestock owners will be helpful in control of human brucellosis. For effective control of brucellosis in state, whole herd vaccination on dairy farms as well as the village level vaccination should be taken up on priority to reduce losses and to minimize the risk of transmission to human population. The brucellosis control in the state will be profitable and cost-effective for society as a whole, including the public health and animal production sectors.

\section{Acknowledgments}

The authors are thankful to Director Research, Chhattisgarh Kamdhenu University for providing financial assistance under Rastriya 
Krishi Vikas Yojna project to carry out the present work.

\section{References}

Chand P and Chhabra R (2013) Herd and individual animal prevalence of bovine brucellosis with associated risk factors on dairy farms in Haryana and Punjab in India. Tropical animal health and production 45(6): 1313-19.

Colmenero J D, Munoz-Roca N L, Bermudez P, Plata A, Villalobos A and Reguera J M (2007) Clinical findings, diagnostic approach and outcome of Brucella melitensis epididymo-orchitis. Diagnostic microbiology and infectious disease 57(4): 367-72.

Dean A S, Crump L, Greter H, Schelling E and Zinsstag J (2012) Global burden of human brucellosis: a systematic review of disease frequency. PLoS neglected tropical diseases 6(10): e1865.

Dhand N K, Gumber S, Singh B B, Aradhana, Bal M S, Kumar H, Sharma D R, Singh J and Sandhu K S (2005) A study on the epidemiology of brucellosis in Punjab (India) using Survey Toolbox. Revue scientifique et technique/Office international des epizooties 24: 879-85.

Douphrate D I, Hagevoort G R, Nonnenmann M W, Kolstrup C L, Reynolds S J, Jakob M and Kinsel M (2013) The dairy industry: a brief description of production practices, trends, and farm characteristics around the world. Journal of Agromedicine 18(3): 187-97.

FAOSTAT (2015) Milk total production in India.

Franc K A, Krecek R C, Hasler B N and Arenas-Gamboa A M (2018) Brucellosis remains a neglected disease in the developing world: a call for interdisciplinary action. $B M C$ public health 18(1): 125.

Godfroid J, Nielsen K and Saegerman C
(2010) Diagnosis of Brucellosis in Livestock and Wildlife. Croatian medical journal 51: 296-305.

Hugh-Jones M E (2000) Zoonoses, Recognition, Control and Prevention. $1^{\text {st }}$ Ed. Edited by Hugh-Jones, M.E., Hubbert, W.T. and Hagstad, H.V. Blackwell Publishing Company, Iowa State Press. pp. 7.

Hull N C and Schumaker B A (2018) Comparisons of brucellosis between human and veterinary medicine. Infection ecology and epidemiology 8(1): 1500846.

Jagapur R V, Rathore R, Karthik K and Somavanshi R (2013) Seroprevalence studies of bovine brucellosis using indirectenzyme-linked immunosorbent assay (i-ELISA) at organized and unorganized farms in three different states of India. Veterinary World 6(8): 550-53.

Jain L, Kumar V, Chaturvedi S, Roy G and Barbuddhe S B (2019) Seroprevalence of brucellosis in bovines of Chhattisgarh, India. Indian Journal of Animal Research 53(2): 255-59.

Kumar N, Pal B C, Yadav S K, Verma A K, Jain U and Yadav G (2009) Prevalence of bovine brucellosis in Uttar Pradesh, India. Journal of Veterinary Public Health 7(2): 129-31.

Nitu, Maiti S K and Krishna M (2013) Seroepidemiological and therapeutic aspects of Brucellosis (Brucella abortus) in Cattle and Buffaloes. Journal of Animal Research 3(1): 65-74.

OIE (World Health Organization for Animal Health) (2017) World Animal Health Organization. One Health: Neglected Zoonoses-FAO-APHCA/OIE Regional Technical Workshop on the Prevention and Control of Animal Brucellosis and Tuberculosis in Asia 11- 13 September, 2017.

OIE (World Health Organization for Animal 
Health) (2016) Infection with Brucella abortus, B. melitensis and B. suis. Chapter 2.1.4. - OIE Manual of Diagnostic Tests and Vaccines for Terrestrial Animals. OIE, Paris, France. Patel M D, Patel P R, Prajapati M G, Kanani A N, Tyagi K K and Fulsoundar A B (2014) Prevalence and risk factor's analysis of bovine brucellosis in periurban areas under intensive system of production in Gujarat, India. Veterinary World 7(7): 509-16.

Rahman M S, Hahsin M F A, Ahasan M S, Her M, Kim J Y, Kang S I and Jung S C (2011) Brucellosis in sheep and goat of Bogra and Mymensingh districts of Bangladesh. Korean Journal of Veterinary Research 51(4): 277-80.

Sadhu D B, Panchasara H H, Chauhan H C, Sutariya D R, Parmar V L and Prajapati H B (2015) Seroprevalence and comparison of different serological tests for brucellosis detection in small ruminants. Veterinary world 8(5): 561 66.

Sai P, Shakya S, Chandrakar C and Ali S L (2018) Sero-prevalence of brucellosis in small ruminants and human in Chhattisgarh. Journal of Animal Research 8(3): 531-35.

Saini S S, Sharma J K and Kwatra M S (1992) Assessment of some management factors responsible for prevalence of brucellosis among traditionally managed animal population of Punjab. Indian Journal of Animal Sciences 62(9): 832-34.
Shakya S, Joshi R K and Ali S L (1995) Seroepidemiology survey of bovine brucellosis in a village of Madhya Pradesh. Indian Veterinary Journal 72: 1327-28.

Shome R, Triveni K, Swati S, Ranjitha S, Krithiga N, Shome B R, Nagalingam $\mathrm{M}$, Rahman $\mathrm{H}$ and Barbuddhe S B (2019) Spatial seroprevalence of bovine brucellosis in India - A large random sampling survey. Comparative Immunology, Microbiology and Infectious Diseases 65: 124-27.

Shome R, Padmashree B S, Krithiga N, Triveni K, Sahay S, Shome B R, Singh $P$ and Rahman H (2014) Bovine brucellosis in organized farms of India An assessment of diagnostic assays and risk factors. Advances in Animal and Veterinary Sciences 2: 557-64.

Singh B B, Dhand N K and Gill J P S (2015) Economic losses occurring due to brucellosis in Indian livestock populations. Preventive veterinary medicine 119(3-4): 211-15.

Snedecor G W and Cochran W G (1994) Statistical Methods. Eighth Edition, Iowa State University Press, Iowa, USA.

Ul-Islam M R, Gupta M P, Filia G, Sidhu P K, Shafi T A, Bhat S A, Hussain S A and Mustafa R (2013) Seroepidemiology of brucellosis in organized cattle and buffaloes in Punjab (India). Advances in Animal and Veterinary Sciences 1(3S): 5-8.

\section{How to cite this article:}

Sanjay Shakya, Anil Patyal, Bhoomika, Choodamani Chandrakar, Sandeep Indurkar and Dhirendra Bhonsle. 2020. Seroprevalence of Brucellosis in Large and Small Ruminants in Chhattisgarh state, India. Int.J.Curr.Microbiol.App.Sci. 9(06): 3303-3309. doi: https://doi.org/10.20546/ijcmas.2020.906.393 